\title{
Proatherosclerotic Effect of the $\alpha 1$-Subunit of Soluble Guanylyl Cyclase by Promoting Smooth Muscle Phenotypic Switching
}

Maria Segura-Puimedon, * Evanthia Mergia, ${ }^{\dagger}$ Jaafar Al-Hasani, * Redouane Aherrahrou, * Stephanie Stoelting, * Felix Kremer, * Jennifer Freyer, ${ }^{*}$ Doris Koesling, ${ }^{\dagger}$ Jeanette Erdmann, ${ }^{*}$ Heribert Schunkert, ${ }^{\ddagger}$ Cor de Wit, ${ }^{\S}$ and Zouhair Aherrahrou*

From the Institute for Integrative and Experimental Genomics* and the Department of Physiology, ${ }^{\S}$ University of Lübeck, DZHK (German Centre for Cardiovascular Research), Partner Site Hamburg/Kiel/Lübeck, University Heart Centre Lübeck, Lübeck; the Department of Pharmacology, ${ }^{\dagger}$ Ruhr-University Bochum, Bochum; and the German Heart Center, ${ }^{\ddagger}$ Technical University of Munich, DZHK (German Centre for Cardiovascular Research), Partner Site Munich Heart Alliance, Munich, Germany

Accepted for publication April 19, 2016.

Address correspondence to Zouhair Aherrahrou, Ph.D., Institute for Integrative and Experimental Genomics, University of Lübeck, MariaGoeppert-Strasse 1, 23562 Lübeck, Germany. E-mail: zouhair.aherrahrou@iieg.uniluebeck.de.

\begin{abstract}
Soluble guanylate cyclase ( $\mathrm{sGC}$ ), a key enzyme of the nitric oxide signaling pathway, is formed as a heterodimer by various isoforms of its $\alpha$ and $\beta$ subunit. GUCY1A3, encoding the $\alpha 1$ subunit, was identified as a risk gene for coronary artery disease and myocardial infarction, but its specific contribution to atherosclerosis remains unclear. This study sought to decipher the role of Gucy $1 a 3$ in atherosclerosis in mice. At age 32 weeks and after 20 weeks of standard or high-fat diet, Gucy $1 a 3^{-/-} / \mathrm{Ldlr}^{-/-}$mice exhibited a significant reduction of the atherosclerotic plaque size at the aortic root and the aorta for high-fat diet animals as compared with $\mathrm{Ldlr}^{-1-}$ control mice. Collagen content in plaques in the aortic root was reduced, suggesting an alteration of smooth muscle cell function. Proliferation and migration were reduced in Gucy $1 \mathrm{a3}^{-1-}$ primary aortic smooth muscle cells (AoSMCs), and proliferation was also reduced in human AoSMCs after inhibition of sGC by $1 \mathrm{H}-[1,2,4]$ oxadiazolo [4,3-a] quinoxalin-1-one. Gucy1a3 deficiency in AoSMCs prevents their phenotypic switching, as indicated by the differential expression of marker proteins. The inherited Gucy $1 \mathrm{a3}^{-/-}$loss exerts an atheroprotective effect. We suggest that $\mathrm{sGC}$ activity promotes the phenotypic switching of smooth muscle cells from a contractile to a synthetic state, fostering the formation of atherosclerosis. Preventing this switch by sGC inhibition may provide a novel target in atherosclerotic disease. (Am J Pathol 2016, 186: 2220-2231; http://dx.doi.org/ 10.1016/j.ajpath.2016.04.010)
\end{abstract}

Atherosclerosis is perceived as a chronic disease arising from endothelial dysfunction, inflammation, and accumulation of foam cells in the media of the arterial wall. In more advanced lesions, smooth muscle cells (SMCs) undergo a transformation from a contractile to a synthetic phenotype characterized by proliferation, migration to the intima, and production of extracellular matrix to form a fibrous cap. ${ }^{1-4}$ The development of atherosclerosis is influenced by environmental and genetic factors. Over the past few years, genome-wide association studies have successfully identified loci associated with coronary artery disease, including the GUCY1A3 locus. ${ }^{5-11}$ Moreover, a digenic mutation in GUCY1A3 and CCT7 was identified as the cause of premature myocardial infarction in a family study. ${ }^{12}$
GUCY1A3 encodes the $\alpha 1$-subunit of the soluble guanylate cyclase (sGC), which forms a heterodimer in conjunction with the $\beta$-subunit. Expression studies revealed that the $\alpha 1$-subunit is ubiquitously expressed in the cardiovascular system. The $\beta$-subunit also associates with the $\alpha 2$-subunit, which is, however, expressed at lower

\footnotetext{
Supported by the German Federal Ministry of Education and Research in the context of the e:Med program (e:AtheroSysMed and sysINFLAME), the FP7 European Union project CVgenes@target (261123), and a Fondation Leducq grant (CADgenomics: Understanding Coronary Artery Disease Genes, 12CVD02), and the German Research Foundation cluster of excellence Inflammation at Interfaces.

C.d.W. and Z.A. contributed equally to this work as senior authors.

Disclosures: None declared.
} 
levels. ${ }^{13,14}$ The primary activator of $\mathrm{sGC}$ is nitric oxide (NO), a signaling molecule specifically relevant in the pathogenesis of atherosclerosis. NO is synthesized by nitric oxide synthases (endothelial, neuronal, and inducible). Interestingly, the eNOS locus was also identified by genome-wide association studies to be associated with coronary artery disease. ${ }^{15}$ NO diffuses across membranes binding to the heme cofactor of sGC, which activates this enzyme. The resulting increase in cGMP modulates the activity of phosphodiesterase, ion-gated channels, or protein kinases such as cGKI/PKG1 (cGMP-dependent protein kinase type I) to exert important physiological functions. ${ }^{16,17}$

Previous studies have sought to decipher the role of the NO-sGC-cGMP pathway in atherosclerosis. ${ }^{18-25} \mathrm{NO}$ is generally considered to prevent atherosclerosis by inhibiting SMC proliferation and migration, platelet aggregation, and leukocyte adhesion. ${ }^{26}$ However, multiple studies have reported contradictory results, due in part to the differing contributions of specific cell types and the gene(s) of interest in the pathway. nNOS and eNOS are thought to be atheroprotective, ${ }^{18-21}$ whereas iNOS and cGKI are reportedly proatherosclerotic. ${ }^{22,23}$ Specifically, studies using tissuespecific knockout mice revealed that SMCs play a decisive role in the proatherosclerotic role of cGKI. ${ }^{24,25}$ Analyses of cell proliferation and migration also highlight the complexity of NO signaling, which can exert opposing effects depending on its concentration and site of action. ${ }^{27-29}$ In general, low NO concentrations stimulate cell proliferation and survival, whereas higher concentrations inhibit proliferation. ${ }^{30,31}$

To date, no studies have characterized the role of sGC subunits on atherosclerosis. Consequently, the specific role of GUCY1A3 in atherosclerosis remains incompletely understood. In this study, we assessed the effect of complete GUCY1A3 deficiency on atherosclerosis. To this end, we crossed Gucyla3 $3^{-1-}$ mice into the $\mathrm{Ldll}^{-1-}$ atherogenic background and examined the development of atherosclerotic lesions. Furthermore, we performed in vitro studies of migration and proliferation to obtain mechanistic insight into the role of Gucyla3 in primary aortic smooth muscle cells (AoSMCs). In addition, we studied the expression of genes of the NO-cGMP-cGKI signaling pathway and marker genes characterizing smooth muscle phenotype.

\section{Materials and Methods}

\section{Experimental Animals}

All animal experiments were performed in accordance with the German animal studies committee of SchleswigHolstein. C57BL/6J mice [wild type (WT)], and $L d l r^{-l-}$ mice were purchased from the Jackson Laboratory (Bar

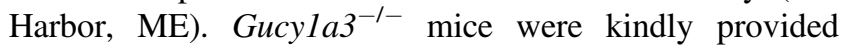
by Dr. Koesling (Ruhr-University Bochum, Bochum, Germany). ${ }^{32}$ Gucyla3 $^{-1-}$ mice were bred into the $\mathrm{Ldlr}^{-1-}$ atherogenic background to generate $G u c y l a 3^{-1-} \mathrm{Ldlr}^{-1-}$ mice.

The genotyping of the Gucyla3 gene was performed as previously described. ${ }^{32}$ For $L d l r^{-l-}$ mice, three primers were used and the PCR was performed according to the standard protocol from the Jackson Laboratory.

\section{Atherosclerosis Study}

Atherosclerotic plaque analysis was performed in females. Four different genotypes were used for the study: WT,

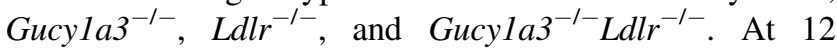
weeks of age, and after plasma collection, each genotype was divided in two groups ( $n=8$ to 12 per group) and fed standard chow diet (SD) or Western type high-fat diet (HFD) containing $0.2 \%$ cholesterol and $21.2 \%$ cocoa butter (Harlan, Paderborn, Germany). During the study, animals were weighted every 2 weeks. At the end of the experiment, animals were euthanized after 20 weeks of diet by an overdose of isoflurane and cervical dislocation. Animals were perfused with phosphate-buffered saline (PBS), $\mathrm{pH} 7.4$ (Lonza, Cologne, Germany), and the whole heart-aorta until the iliac bifurcation was collected and fixed in $4 \%$ paraformaldehyde for histological analysis. Plasma and several organs were obtained for posterior analysis. Tail and liver were used for regenotyping of the animals.

\section{Lipid Metabolism Analysis}

Lipid metabolism was assessed at the start and the end of the experiment for all four genotypes. Total cholesterol, highdensity lipoprotein (HDL), direct low-density lipoprotein, and triglycerides from the end of experiment samples were analyzed using a Roche-Cobas 702 machine at the Institute for Clinical Chemistry of the University of Lübeck. Total cholesterol, HDL, non-HDL, and triglycerides levels in plasma from the start of the experiment samples were analyzed by high-performance liquid chromatography at the Department of Endocrinology and Metabolic Diseases at University of Leiden because of reduced sample amount.

Oxidized low-density lipoprotein was also analyzed at the end of the experiment in plasma samples from all groups under

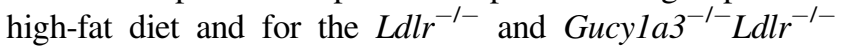
animals under standard diet. The Mouse Oxidized Lowdensity Lipoprotein (OxLDL) enzyme-linked immunosorbent assay kit (CUSABIO, Baltimore, MD) was used following the manufacturer's instructions.

\section{Blood Pressure Measurements}

Systolic, mean, and diastolic blood pressure were measured at the end of the atherosclerosis study in high-fat diet female animals by using tail cuff plethysmography (BP-98A; Softron Co., Tokyo, Japan). Measurements were taken from a total of $10 \mathrm{Ldlr}^{-/-}$, five $\mathrm{Gucyla}^{-1-} \mathrm{Ldlr}^{-1-}$, five WT, and five Gucyla3 $^{-1-}$ animals. For habituation, mice were trained 
daily ( 7 days). After the training period, 10 measurements per mouse were recorded daily for 5 days.

\section{Cytokine Analysis}

The amount of cytokines present in the plasma of the four genotypes after high-fat diet was assayed after pooling 40 $\mu \mathrm{L}$ each from five animals per group. The Mouse Cytokine Array Panel A kit (R\&D Systems, Minneapolis, MN) was performed according to the manufacturer's instructions. The same procedure was used to analyze the cytokines present in the 96-hour proliferation medium of WT and Gucyla3 ${ }^{-1-}$ mouse aortic smooth muscle cells.

\section{Atherosclerotic Plaque Analysis}

To evaluate atherosclerotic lesions, two methods were used: at the aortic root serial cryosections $(10 \mu \mathrm{m})$ were obtained starting below the aortic roots until the proximal aorta below the aortic arch and, in addition, the so-called en face analysis.

The atherosclerotic lesion area was determined at the aortic root by using oil red-O staining. Mean lesion area was calculated from 10 sections at $40-\mu \mathrm{m}$ intervals, starting at the appearance of at least two aortic valves. For the en face analysis, the thoraco-abdominal aortas were analyzed. The adventitial tissue was removed and the aorta was opened longitudinally. Lipid-rich intraluminal lesions were stained with oil red O. Aortas were pinned into a $2.5 \%$ agarose gel and color pictures were captured using a Leica M-80 microscope and Leica IC80 HD camera using the Leica Application Suite (LAS) version 4.2 software (Leica Microsystems, Wetzlar, Germany). Images were analyzed with the GIMP software version 2.6 (The GIMP Development Team) and the amount of aortic lesion formation in each animal was measured as percentage lesion area per total area of the aorta.

The same approach was also used to determine collagen content of the plaques, five sections at $40-\mu \mathrm{m}$ intervals were stained using Masson's Trichrome staining (Sigma, St. Louis, MO) following the manufacturer's instructions. Collagen content was determined as a percentage of the total plaque, after intensity determination of collagen presence. Images were obtained using Olympus IX70 microscope coupled to the Olympus U-TV0.5XC-3 video camera and using the Leica Qwin Imaging software version 3 (Leica Microsystems).

The presence of macrophages was determined in five sections at $40-\mu \mathrm{m}$ intervals after immunohistochemical staining using a rat monoclonal anti-monocyte and macrophage antibody (MOMA-2, 1:500; Abcam, Cambridge, UK). Polyclonal rabbit anti-rat-horseradish peroxidase (HRP) (1:100; Dako, Hamburg, Germany) was used as a secondary antibody and ImmPACT NovaRED substrate (Vector Laboratories, Burlingame, CA) was used for visualization of HRP following the manufacturer's instructions after an exposure time of 5.5 minutes. Macrophage content was determined as a percentage of the total plaque. Images were obtained using a Keyence BZ-9000 microscope with BZII software version 1.41 (Keyence Deutschland GmbH, Neu-Isenburg, Germany). Plaque areas were delimited using GIMP software version 2.6 (The GIMP Development Team) and MOMA-2 intensity was analyzed with an in-house MATLAB script.

All of the atherosclerotic plaque analyses were performed blind to the given genotype.

\section{Primary Aortic SMC Isolation from Mice}

Murine aortic smooth muscle cells (AoSMCs) were isolated

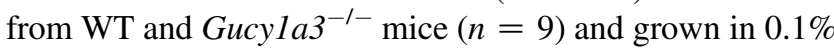
pork gelatin in PBS coated surfaces (Sigma), DMEM-GlutaMAX (Gibco, Life Technologies, Ober-Olm, Germany) supplemented with $20 \%$ fetal bovine serum, EU Professional (PAN Biotech, Aidenbach, Germany), and 1\% penicillin streptomycin (Merck Millipore, Darmstadt, Germany). Trypsin-EDTA was used for passaging (Gibco, Life Technologies). Primary cells were used for experiments until passage 12. To ensure population purity, immunohistochemistry using the SMC marker sm22 $\alpha$ (Abcam) at 1:100 dilution was performed. Anti-goat HRP antibody (Cell Signaling) at 1:200 dilution was used as secondary antibody and Liquid DAB + substrate Chromogen system (Dako) was used for visualization of HRP. Control sections were processed in the absence of primary antibodies.

\section{AoSMC Proliferation Assay}

The previously isolated primary AoSMCs were used to perform proliferation assays. Twenty-thousand cells per well in triplicate were seeded in 12-well plates per time-point (4, 24, 48, 72, and 96 hours). Two methods were used for quantification. In the first, cells were trypsinized using Trypsin-EDTA (Gibco, Life Technologies) and counted using the Newbauer chamber (Marienfeld). In the second method, cells were fixated with $4 \%$ formaldehyde (Merck) for 5 minutes, treated with Triton-X-100 $0.1 \%$ in PBS for 10 minutes, and washed once with PBS (Lonza). Finally, cells were stained with a 1:10,000 DAPI (Sigma) to PBS dilution for 10 minutes. Ten representative pictures per well were taken using a Keyence BZ-9000 microscope with BZII software version 1.41 (Keyence Deutschland $\mathrm{GmbH})$. Cells were counted with the ImageJ software version $1.48 \mathrm{v}$ (NIH, Bethesda, MD; http:// imagej.nih.gov/ij) using an in-house script for DAPI signal. The total number of cells per well was extrapolated from the area of the analyzed pictures to the total area of the well. All experiments were performed in triplicate and for at least three independent times.

\section{AoSMC Migration Assay}

Cell migratory capability of previously isolated AoSMCs was assayed using the xCELLigence Biosensor System. 
Experiments were performed in an RTCA D instrument (Roche Diagnostics, Basel, Switzerland) placed in a $5 \%$ $\mathrm{CO}_{2}$ humidified incubator maintained at $37^{\circ} \mathrm{C}$. Cell migration was assessed using specifically designed 16-well plates (CIM-plate 16; Roche Diagnostics) with 8 - $\mu$ m pores. Fortythousand cells per well were seeded in the upper chamber in serum-free medium conditions. FCS medium (20\%) was used as chemoattractant and serum-free medium as control in the lower chamber. Data were analyzed using RTCA software version 1.2 (Acea Biosciences Inc., San Diego, CA). All experiments were performed in quadruplicate and for at least three independent times.

\section{Effect of the NO Donor SNP and SGC Inhibitor ODQ on SMC Proliferation}

Human aortic smooth muscle cells (HuAoSMCs; Invitrogen) were grown in Medium 231 (Gibco, Life Technologies) supplemented with smooth muscle growth supplement (Gibco, Life Technologies) and 1\% penicillin streptomycin (Merck Millipore). Trypsin-EDTA was used for passaging (Gibco, Life Technologies) together with TN trypsin neutralizer solution $(1 \times)$ (Gibco, Life Technologies). Mouse AoSMCs were harvested as described above. Cells were used for experiments until passage 9 . $1 \mathrm{H}-[1,2,4]$ oxadiazolo $[4,3-\mathrm{a}]$ quinoxalin-1-one (ODQ; Cayman Chemical) was dissolved in $30 \mathrm{mg} / \mathrm{mL}$ dimethyl formamide (VWR) following manufacturer's instructions and used at final concentrations of 10 or $20 \mu \mathrm{mol} / \mathrm{L}$ applied for 24 or 48 hours. Sodium nitroprusside (SNP; Sigma-Aldrich) was used at concentrations of 50 to $200 \mu \mathrm{mol} / \mathrm{L}$ for 24 or 48 hours. The proliferation assay was quantified using the DAPI staining method, as explained above. All experiments were performed with six technical replicates and for at least three independent times.

\section{RNA Isolation and Real-Time Quantitative PCR}

Total RNA was isolated from mouse AoSMCs and organs using the RNeasy Plus Mini Kit (Qiagen, Venlo, the Netherlands), following the manufacturer's instructions. Total RNA was then reverse transcribed into cDNA and changes in mRNA levels were determined using the $\Delta \Delta \mathrm{Ct}$ method, as previously described. ${ }^{33}$ Glyceraldehyde-3phosphate dehydrogenase or $\beta$-actin was used as housekeeping genes. All experiments were performed in triplicate and for at least three independent times. Sequences of the primer pairs used for amplification are denoted in Table 1.

\section{Protein Isolation and Western Blot}

Protein was isolated from mouse AoSMCs and organs, as previously described. ${ }^{33}$ Protein $(15 \mu \mathrm{g})$ was used and separated in an SDS-PAGE gel and transblotted. After blocking with 5\% skim milk, blots were incubated with the primary antibodies: anti-PKG1 1:200 (Cell Signaling), anti-calponin 1:200 (Sigma), anti-osteopontin 1:200
Table 1 Sequences of the Primer Pairs Used for Amplification

\begin{tabular}{|c|c|c|c|}
\hline $\begin{array}{l}\text { Primer } \\
\text { name }\end{array}$ & Primers & $\begin{array}{l}\text { Length } \\
\text { (bp) }\end{array}$ & Position \\
\hline Gucy1a3-F & $5^{\prime}$-CGACTGAACCTTGCACTTCA-3' & 114 & Exon 3 \\
\hline Gucy1a3-R & 5'-TGCTGCAATTGCTTCTTCTG-3' & & Exon 4 \\
\hline Gucy1a2-F & $5^{\prime}$-CGGAGTACGAATGCCACGAT-3' & 236 & Exon 7 \\
\hline Gucy1a2-R & $5^{\prime}$-GTGGCTTTGGGTCAGTCCTT-3' & & Exon 8 \\
\hline Gucy1b3-F & $5^{\prime}-$ CACACTGAGAGCCTTGGAGG- $3^{\prime}$ & 77 & Exon 9 \\
\hline Gucy1b3-R & $5^{\prime}-$ TGGCAACAGATGGAGGAAGG - $3^{\prime}$ & & Exon 10 \\
\hline cGKI-F & $5^{\prime}$-GGCCATCGATCGACAATGTTTT-3' & 150 & Exon 4 \\
\hline cGKI-R & $5^{\prime}$-GTCTCTTCGAGGACATCAGCC-3' & & Exon 5 \\
\hline Cnn1-F & $5^{\prime}$-GATGGCCTCAAAGACGGGAT- $3^{\prime}$ & 97 & Exon 2 \\
\hline Cnn1-R & $5^{\prime}$-GGTGCCAGTTCTGAGTTGAC-3' & & Exon 3 \\
\hline Spp1-F & $5^{\prime}$-CAGAATCTCCTTGCGCCACA-3' & 76 & Exon 4 \\
\hline Spp1-R & $5^{\prime}$-TGCTTGGAAGAGTTTCTTGCTT-3' & & Exon $5-6$ \\
\hline Thsd1-F & 5'-GCTCTGTGACTATGTCCTCGG-3' & 98 & Exon 2 \\
\hline Thsd1-R & $5^{\prime}-$ AGTGGAAACCCACTGACACC $-3^{\prime}$ & & Exon 3 \\
\hline
\end{tabular}

$F$, forward; $R$, reverse.

(Abcam), and anti- $\alpha$-tubulin 1:1000 (Abcam), and antiglyceraldehyde-3-phosphate dehydrogenase 1:1000 (Abcam) as control. Appropriate secondary antibodies were then used, and the protein bands were detected using the ECL Prime Western Blotting Detection Reagent (GE Health Care, Little Chalfont, UK) and quantified with ImageJ software version $1.48 \mathrm{v}$ (NIH, Bethesda, MD).

\section{Statistical Analysis}

Data were analyzed using the GraphPad Prism software version 6 (GraphPad Software Inc., La Jolla, CA) and presented as means $\pm \mathrm{SD}$. Pairwise comparisons were used to

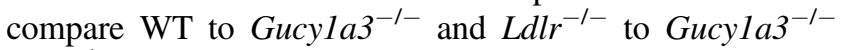
$L d l r^{-l-}$ using unpaired $t$-test. In case of analyzing more than two groups, analysis of variance with Bonferroni multiple comparison correction was performed. Statistical significance was assumed at $P<0.05$.

\section{Results}

\section{Body Mass, Lipid Metabolism, and Arterial Pressure}

Body mass increased starting at an age of 12 to 14 weeks from $18 \mathrm{~g}$ during 20 weeks of standard diet (SD) to $23 \mathrm{~g}$. This gain was enhanced in animals receiving high-fat diet (HFD), and body mass reached approximately $29 \mathrm{~g}$ after 20 weeks. However, Gucyla3-deficiency was without effect and all genotypes exhibited a similar increase of body mass for each diet (Supplemental Figure S1).

Total cholesterol and HDL assessed at the start of the diet were similar in WT and Gucyla3 ${ }^{-1-}$ animals, but a slight reduction of non-HDL and triglycerides was

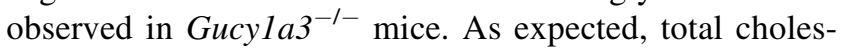
terol, non-HDL, and triglycerides were markedly elevated

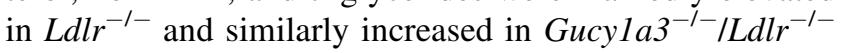
animals (Table 2). During 20 weeks of SD plasma lipid levels did not change markedly and only minor differences 
Table 2 Lipid Metabolism Levels at 12 to 14 Weeks of Age

\begin{tabular}{lllll}
\hline & \multicolumn{2}{l}{ Standard diet } & & \\
\cline { 2 - 5 } Variable & WT $(n=11)$ & $\begin{array}{l}\text { Gucy1a3 } \\
(n=11)\end{array}$ & $\begin{array}{l}\text { Ldlr }^{-/-} \\
(n=14)\end{array}$ & $\begin{array}{l}\text { Gucy1a3 }^{-/-} / \text {Ldlr }^{-/-} \\
(n=20)\end{array}$ \\
\hline Total cholesterol (mmol/L) & $2.33 \pm 0.34$ & $2.14 \pm 0.33$ & $7.04 \pm 1.09$ & $6.82 \pm 1.09$ \\
HDL (mmol/L) & $1.43 \pm 0.20$ & $1.51 \pm 0.25$ & $1.75 \pm 0.43$ & $1.90 \pm 0.22$ \\
Non-HDL (mmol/L) & $0.90 \pm 0.21$ & $0.63 \pm 0.25^{*}$ & $5.30 \pm 1.24$ & $4.97 \pm 1.21$ \\
Triglycerides (mmol/L) & $1.70 \pm 0.97$ & $1.02 \pm 0.26^{*}$ & $2.43 \pm 0.91$ & $2.92 \pm 1.39$ \\
\hline
\end{tabular}

Data are represented as means \pm SD.

${ }^{*} P=0.05$.

$H D L$, high-density lipoprotein; WT, wild type.

were found between Gucyla $3^{-1-}$ mice and their respective controls (Table 3). Twenty weeks of HFD potentiated direct low-density lipoprotein and total cholesterol levels (approximately sevenfold) in $L d l r^{-1-}$ and to a similar

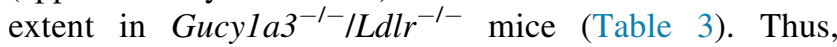

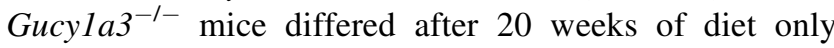
slightly from their respective controls, namely, a small reduction of total cholesterol after SD irrespective of the presence of the LDL receptor and a minor increase in LDL in LDL receptor bearing mice after both diets. More important, differences between $\mathrm{Ldlr}^{-1-}$ and $\mathrm{Gucyla}^{-/-}$, $L d l r^{-1-}$ animals were not observed on HFD and also in such animals receiving SD LDL levels were similar (Table 3). Oxidized low-density lipoprotein was comparable in all HFD

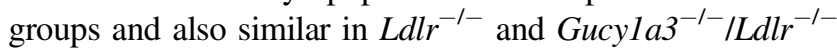
on SD (Table 3).

Cytokines reflect the inflammatory process during the development of atherosclerosis. However, cytokine levels assessed in plasma from animals receiving HFD were comparable in all genotypes after normalization (Supplemental Figure S2).

Deficiency of Gucyla3 is associated with an increase in arterial pressure. $^{32}$ Systolic and diastolic pressures amounted to $119.6 \pm 3.5$ and $85.4 \pm 3.4 \mathrm{~mm} \mathrm{Hg}$, respectively, in $\mathrm{Ldll}^{-1-}$ mice after HFD and were significantly

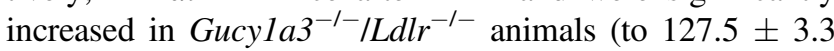
and $90.1 \pm 3.7 \mathrm{~mm} \mathrm{Hg}$, respectively; both $P<0.05$ ).

\section{Reduced Atherosclerosis in Gucy $1 \mathrm{a3}^{-/-} / \mathrm{Ldlr}^{-/-}$Mice}

Plaque area was analyzed at the aortic root in all genotypes after 20 weeks of SD or HFD. As expected, lesions were not

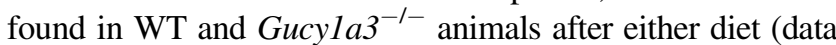
not shown). Atherosclerotic lesions were observed in $\mathrm{Ldlr}^{-l-}$ mice after SD and lesion area was markedly enlarged after

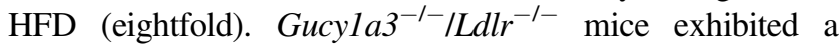
significantly reduced lesion area after both diets (Figure 1A). The reduction was pronounced after SD (by 48\%) but lesion area was also reduced significantly after HFD (by 16\%). Given the previous controversy on the role of the NO pathway in atherosclerosis, ${ }^{18-23}$ to confirm our results and test their reproducibility, we analyzed a second experimental group of animals receiving SD. In this independent experi-

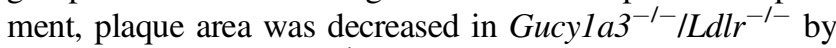
$69 \%$ compared to $\mathrm{Ldll}^{-l-}$ mice, thus confirming the results of the initial series (Figure 1B).

Table 3 Lipid Metabolism Levels at 30 to 32 Weeks of Age

\begin{tabular}{|c|c|c|c|c|}
\hline \multirow[b]{2}{*}{ Variable } & \multicolumn{4}{|l|}{ Genotype } \\
\hline & $\overline{W T}$ & Gucy1a3 $1-$ & $L d l r^{-/-}$ & Gucy $1 a 3^{-/-} /$Ldll $^{-/-}$ \\
\hline \multicolumn{5}{|l|}{ Standard diet } \\
\hline Total cholesterol (mmol/L) & $2.2 \pm 0.20$ & $1.89 \pm 0.27^{\star}$ & $6.08 \pm 0.60$ & $5.32 \pm 0.37^{*}$ \\
\hline $\mathrm{HDL}(\mathrm{mmol} / \mathrm{L})$ & $1.02 \pm 0.067$ & $0.93 \pm 0.12$ & $1.18 \pm 0.15$ & $1.10 \pm 0.14$ \\
\hline $\mathrm{dLDL}(\mathrm{mmol} / \mathrm{L})$ & $0.12 \pm 0.02$ & $0.16 \pm 0.03^{*}$ & $2.17 \pm 0.23$ & $1.99 \pm 0.23$ \\
\hline \multicolumn{5}{|l|}{ High-fat diet } \\
\hline$n$ & 6 & 5 & 8 & 6 \\
\hline Total cholesterol (mmol/L) & $3.04 \pm 0.28$ & $3.31 \pm 0.41$ & $40.95 \pm 8.38$ & $42.94 \pm 5.5$ \\
\hline HDL (mmol/L) & $2.92 \pm 0.35$ & $2.99 \pm 0.35$ & $1.10 \pm 0.39$ & $0.88 \pm 0.17$ \\
\hline $\mathrm{dLDL}(\mathrm{mmol} / \mathrm{L})$ & $0.57 \pm 0.06$ & $0.78 \pm 0.16^{\star}$ & $15.39 \pm 2.95$ & $16.93 \pm 2.14$ \\
\hline
\end{tabular}

Data are represented as means \pm SD.

${ }^{*} P=0.05$.

$\mathrm{dLDL}$, direct low-density lipoprotein; HDL, high-density lipoprotein; oxLDL, oxidized low-density lipoprotein; WT, wild type. 

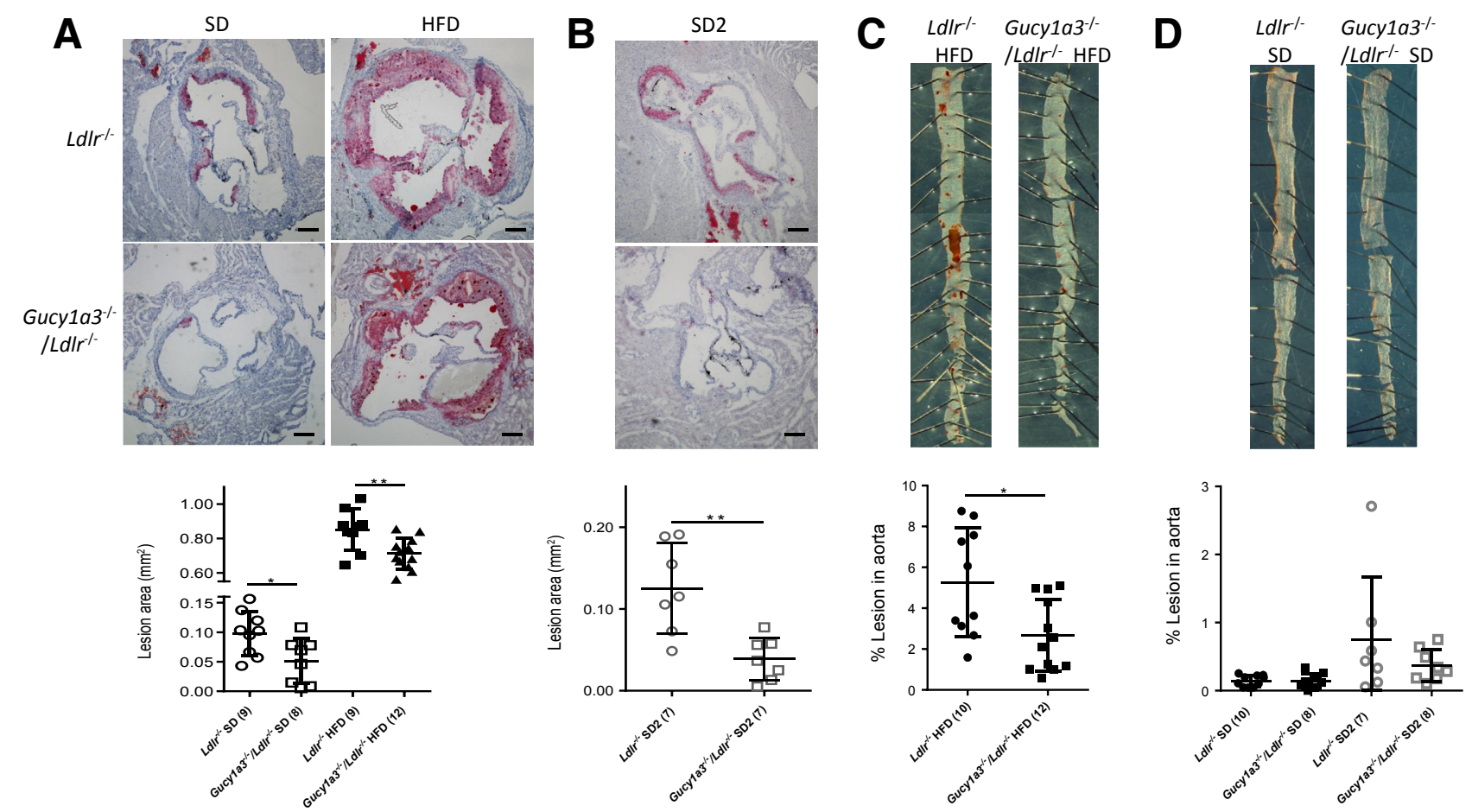

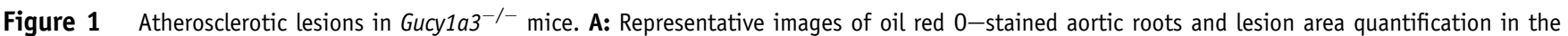
aortic root of animals receiving standard diet (SD) or high-fat diet (HFD). B: Representative images of the oil red 0-stained aortic roots and quantification of the lesion area at the aortic root of an independent group of animals receiving SD. C: Representative images of the oil red 0-stained aortas and quantification of the area covered by plaques in the aorta examined en face in HFD animals. D: Representative images of the oil red 0-stained aortas and quantification of the area covered by plaques (\%) in the aorta examined en face in SD animals. Values of individual animals are additionally depicted (dot or square). Parenthesis indicates number of animals per group. All mice are in a genetic $L d l r$-deficient background $\left(\operatorname{Ldll}^{-/-}\right)$. Data are presented as means \pm SD $(\mathbf{A}-\mathbf{D})$. ${ }^{*} P<0.05,{ }^{* *} P<0.01$. Scale bar $=100 \mu \mathrm{m}(\mathbf{A}$ and $\mathbf{B})$.

In addition, atherosclerosis was quantified by the en face method in the thoracic and abdominal aorta. Lesions constituted $5.26 \% \pm 2.66 \%$ of the total aortic area in $\mathrm{Ldll}^{-1-}$ animals after HFD and this proportion was reduced to

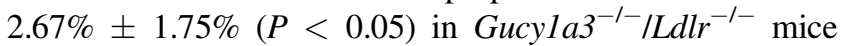

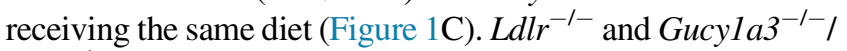
$\mathrm{Ldll}^{-1-}$ animals receiving SD exhibited a low incidence of lesions in the aorta and differences were not observed between genotypes (Figure 1D).

Next, we assessed collagen content by trichrome staining and macrophage numbers by MOMA-2 staining at the aortic root in animals fed HFD. After normalizing for lesion size, we observed a reduced collagen content in Gucyla3 ${ }^{-1-}$ / $\mathrm{Ldlr}^{-1-}$ compared to $\mathrm{Ldlr}^{-1-}$ (Figure 2A). By contrast, macrophage content was not different between genotypes (Figure 2B), suggesting a role for SMCs rather than macrophages in the protective effect of Gucyla3 deficiency.

\section{Reduced Proliferation and Migration in Gucy1a3 $3^{-/-}$ AoSMCs}

We next studied migration and proliferation using isolated SMCs from thoracic aorta (AoSMCs) of WT and Gucyla $3^{-1-}$ animals. AoSMCs were cultured and stained with $\operatorname{Sm} 22 \alpha$ to verify a pure SMC population (Figure $3 \mathrm{~A}$ ). Migration was analyzed in the absence (control) or presence of $20 \%$ fetal bovine serum as a stimulus. Migration was reduced in

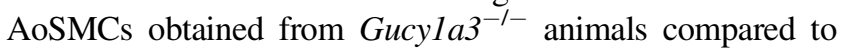
WT in the presence of fetal bovine serum. Without stimulation (control), migration of cells was limited and no difference was evident between genotypes (Figure 3B). Cell proliferation was quantified either manually (Neubauer chamber) or using an automated method after DAPI staining in independent experiment series. Cells started to proliferate after 24 hours in culture, but in both experiments Gucyla3 ${ }^{-1-}$ AoSMCs proliferated significantly less that WT AoSMCs (Figure 3, C and D). Cytokine array analysis performed on medium harvested after 96 hours of growth in culture from WT and Gucyla3 $3^{-/-}$cell cultures revealed no differences between genotypes (Supplemental Figure S3).

\section{Effect of Modulation of the NO Pathway on Proliferation in Mouse and Human AoSMCs}

To further define the role of the NO pathway in SMC proliferation, we treated WT mouse AoSMCs and human aortic smooth muscle cells (huAoSMCs) with the NO donor $\mathrm{SNP}^{34,35}$ or the sGC inhibitor ODQ. ${ }^{32,36}$

Exposure to SNP significantly reduced huAoSMC proliferation after 48 hours of culture with 24 hours of treatment at the highest concentration used $(200 \mu \mathrm{mol} / \mathrm{L})$. After prolongation of the culture time ( 72 hours, with 48 hours of 

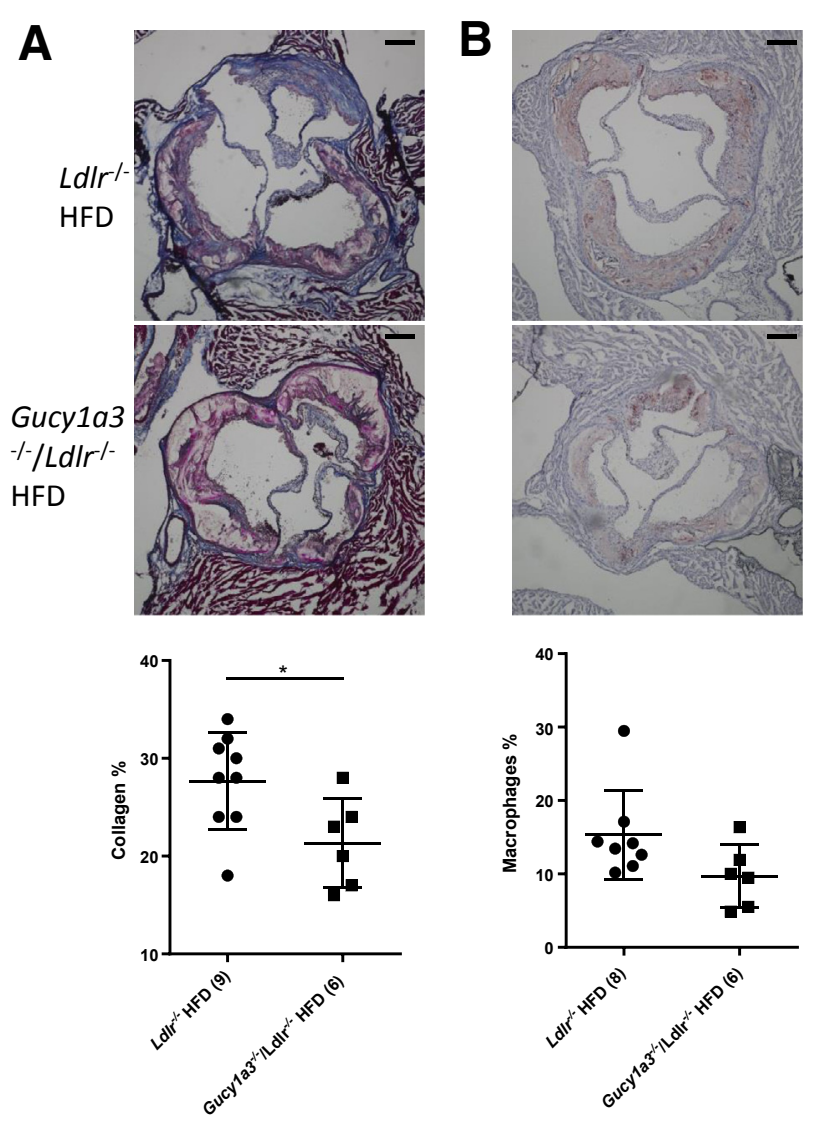

Figure 2 Collagen and macrophages content in atherosclerotic lesions. A: Representative images of trichrome-stained aortic root and quantification of the collagen content. B: Representative images of aortic root after anti-monocyte and macrophage antibody-staining and quantification of the macrophages content. Values of individual animals are additionally depicted (dot or square). Parenthesis indicate number of animals per group. All animals received high-fat diet (HFD). Data are presented as means \pm SD $(\mathbf{A}$ and $\mathbf{B})$. ${ }^{*} P<0.05$. Scale bar $=100 \mu \mathrm{m}(\mathbf{A}$ and $\mathbf{B})$.

treatment), proliferation was attenuated at all SNP concentrations studied (50 to $200 \mu \mathrm{mol} / \mathrm{L}$ ) (Figure 4A). Surprisingly, inhibition of sGC (ODQ) likewise reduced cell proliferation. This attenuation was observed after 44 hours of treatment with $10 \mu \mathrm{mol} / \mathrm{L}$ ODQ compared to the solvent (Figure 4B). In an independent experiment, ODQ treatment was started only 24 hours after seeding. Also in this setting, SMC proliferation was attenuated by ODQ (Figure 4C). Likewise, proliferation of murine aortic SMCs obtained from WT animals was strongly reduced by SNP treatment (Figure 4D). This inhibitory effect of SNP was not affected by ODQ in these cells (Figure 4E). These experiments suggest that high exogenous NO concentrations inhibit proliferation independent of sGC, whereas endogenous $\mathrm{NO}$ stimulates proliferation in a sGC-dependent manner.

\section{Gucy1a3 Deficiency Preserves Expression of Contractile Proteins in Mouse AoSMCs}

The changes in SMC migration and proliferation led us to study the expression of genes that indicate a phenotypic modulation of SMC in the previously isolated WT and

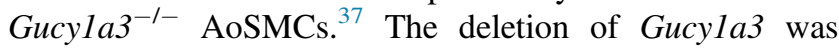
confirmed in Gucyla3 ${ }^{-l-}$ AoSMCs (Figure 5A). The transcriptional expression of a marker of the contractile phenotype (calponin, Cnnl) was strongly enhanced in Gucyla3 $^{-1-}$ AoSMCs (40-fold) compared to WT, whereas genes of markers of the synthetic phenotype (osteopontin, Spp1; thrombospondin, Thsdl) were only modestly induced at the mRNA level (Figure 5A). The enhanced expression of Cnn1 was confirmed at the protein level, because it was not

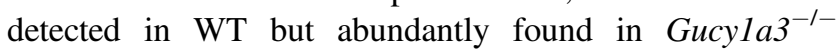
AoSMCs (Figure 5B). $\alpha$-Actin, an additional marker of the contractile phenotype, was also significantly more abundant

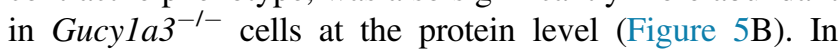
contrast, the level of the synthetic phenotype marker osteopontin was not differentially expressed at the protein level between genotypes (Figure 5B). This suggests that in these AoSMCs the deletion of Gucyla3 preserves a contractile phenotype (ie, the corresponding marker proteins are reduced in WT and proteins are accordingly more abundant in Gucyla3 ${ }^{-1-}$ SMCs).

To determine whether the preserved expression of markers of the contractile phenotype was specific for cultured AoSMCs, which mimic the intimal SMCs rather than medial AoSMCs present in basal conditions in the aorta, we analyzed their expression levels in the thoracic

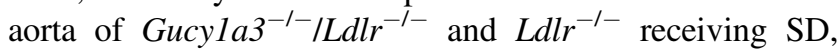
where plaque area was minimal in both genotypes (Figure 1D). In SMCs harvested from this lesion-free aorta, transcriptional expression of calponin was not different between genotypes (Figure 5C) and accordingly expression of osteopontin and thrombospondin was not detected in this tissue (data not shown), indicating that the contractile phenotype remained preserved also in the presence of Gucyla3 under these conditions.

\section{Expression of Genes of the NO-sGC-cGKI Pathway in Mouse AoSMCs}

Finally, we studied the expression of genes of the NO-cGMP pathway in cells and atherosclerotic tissues. Genes of the NO-sGC-cGKI pathway were up-regulated at

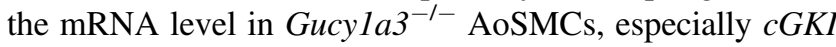
(Figure 6A). cGKI, alias protein kinase G (PkG1), overexpression was also observed at the protein level because it

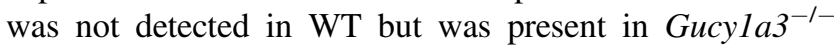
AoSMCs (Figure 6A).

To determine whether the overexpression was specific for cultured AoSMCs mimicking the intimal state of the atherosclerosis lesion, the near lesion-free thoracic aorta from Gucy $1 a 3^{-1-} / L_{d l r^{-1-}}$ and $\mathrm{Ldll}^{-1-}$ animals receiving SD was examined as outlined before. Gucyla3 deficiency was confirmed and, in contrast to cultured AoSMCs, the transcriptional expression of cGKI was not enhanced in this tissue derived from $G u c y l a 3^{-1-}$ but rather slightly reduced compared to WT tissue (Figure 6B). No differential 
A

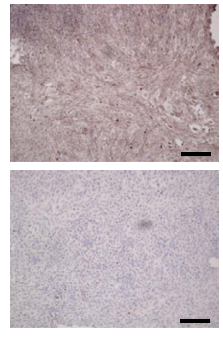

C

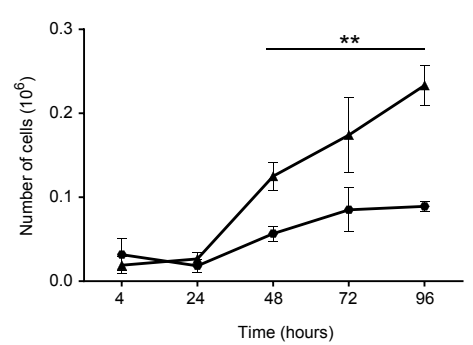

B

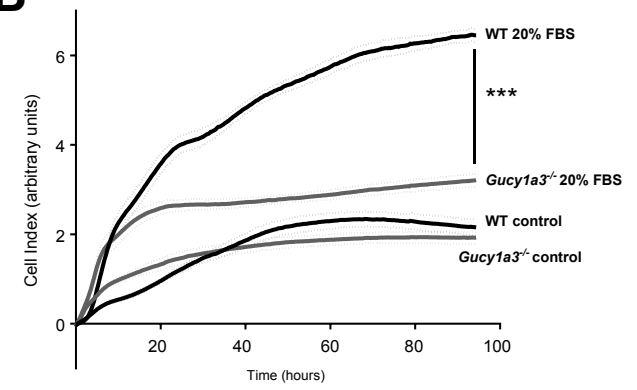

D

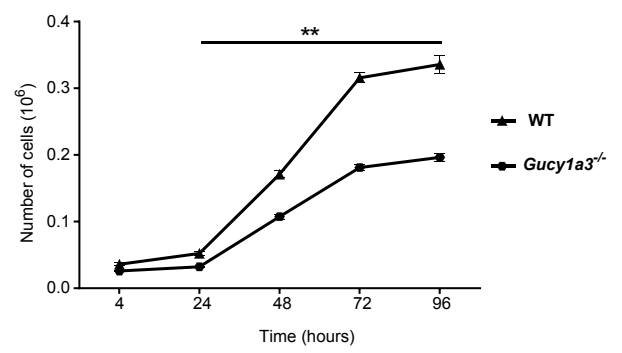

Figure 3 Proliferation and migration of isolated murine aortic smooth muscle cells (SMCs) in culture. A: Top panel: Smc22 $\alpha$ immunostaining. Bottom panel: control without primary antibody. B: Migration assay using a commercially available platform (xCELLigence; Acea Biosciences Inc., San Diego, (A). Migration was analyzed in the presence of fetal bovine serum (FBS; $20 \%$ ) used as chemoattractant or without FBS (control) and quantified as cell index, a relative change in measured electrical impedance to represent a quantitative measure of cell number present in a well. C and D: Proliferation of SMCs, cell number was assessed using a neubauer chamber (C) or in a separate experimental series after staining with DAPI (D). ${ }^{*} P<0.01,{ }^{*} * *<0.001$. Scale bar $=$ $100 \mu \mathrm{m}$ (A). WT, wild type. regulation was observed for Gucylb3 or Gucyla2 (Figure 6B). In nonvascular tissue (heart) deficiency of Gucyla3 was confirmed and differential regulation of the genes of the NO-sGC-cGKI pathway was not observed (Figure 6C). Likewise, cGKI was similarly expressed at the protein level in heart tissue obtained from $\mathrm{Ldlr}^{-I-}$ and $\mathrm{Ldlr}^{-/-}$ Gucyla3 ${ }^{-1-}$ (Figure 6D).

\section{Discussion}

This study demonstrates that deletion of the $\alpha 1$-subunit of the sGC, which is encoded by Gucyla3, attenuates atherosclerotic lesion formation in a murine model in vivo. This protective effect was most pronounced at moderate proatherosclerotic conditions $\left(\mathrm{Ldll}^{-1-}\right.$ genetic background with normal chow) but still present during severe atherosclerosis ( $L d l r^{-1-}$ fed hypercholesteremic chow). This surprising observation suggests that Gucyla3 promotes the formation of atherosclerotic lesions in mice. We suggest that this deleterious effect is related to a function of sGC in SMCs, which promotes their migration and proliferation because SMCs deficient for Gucyla3 proliferated less and exhibited a reduced migratory activity in vitro. A similar antiproliferatory effect was also observed in human SMCs by pharmacological inhibition of the sGC. On the contrary, high concentrations of exogenously applied NO exhibited a similar inhibitory potency, suggesting that NO exerts opposite effects depending on its concentration. Gene expression profiling indicates that the reduced proliferative activity of Gucyla3 deficient SMCs is related to a preservation of the contractile phenotype of SMCs. Accordingly, our results indicate that $\mathrm{sGC}$ activity is required to promote the switch from the contractile to the synthetic phenotype, which aggravates under proatherosclerotic condition lesion development.

We assessed the role of $\mathrm{sGC}$ in atherosclerosis because GUCY1A3 is among the genes identified in human genome-wide association studies to contribute to the risk of coronary artery disease and myocardial infarction (ie, the major manifestations of atherosclerosis). 5,12,38 Furthermore, a rare loss-of-function mutation in GUCY1A3 was identified in an extended family presenting with premature myocardial infarction. ${ }^{12}$ Thus, we expected an aggravated atherosclerosis in Gucyla3 deficient mice. However, we observed surprisingly the opposite in our initial experimental series (ie, a markedly reduced atherosclerotic lesion size at the aortic

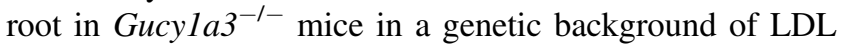
receptor deficiency). This reduction was also demonstrated throughout the aorta at augmented atherosclerotic conditions (high-fat diet) and was replicated in an independent group of animals at modest atherosclerotic conditions (standard diet). Thus, under atherogenic conditions complete Gucyla3 deficiency exerts a protective effect in the aorta. Interestingly, postnatal SMC-specific deletion of the cGKI, which is an important target of cGMP produced by sGC, likewise attenuated atherosclerosis in ApoE-deficient mice. ${ }^{25}$ This indicates that the activation of the NO-sGC-cGMP pathway initiates in a cGMP/cGKI-dependent manner specifically in SMC proatherosclerotic mechanisms. At first glance, the current findings seem to be at odds with our previous demonstration that a loss-of-function mutation of $G U C Y 1 A 3$ and dysfunctional nitric oxide signaling increases the risk of myocardial infarction. ${ }^{12}$ However, in that previous study, NO-induced platelet inhibition was impaired in Gucyla3deficient mice; consequently, platelet aggregation accelerated and thrombus formation enhanced, which is perfectly consistent with an increased risk of the acute event 
A

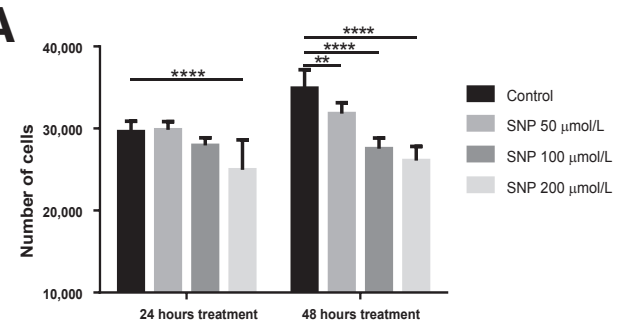

C

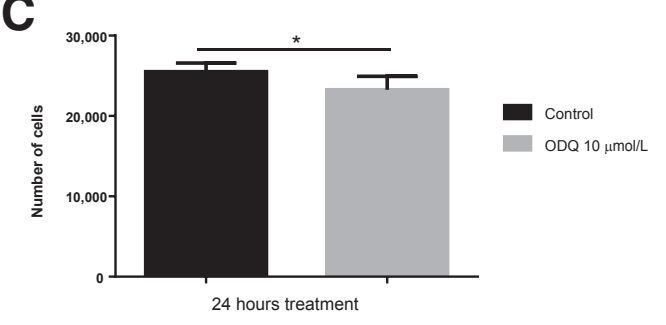

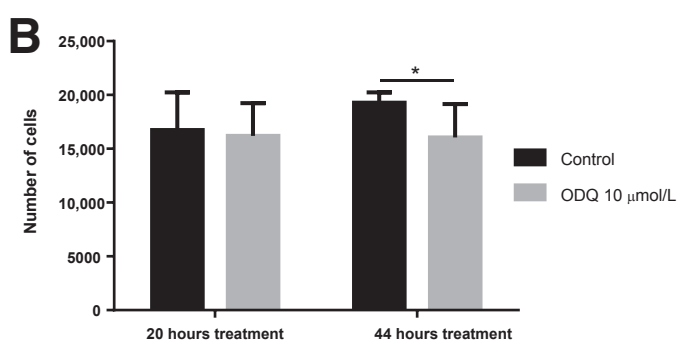

D

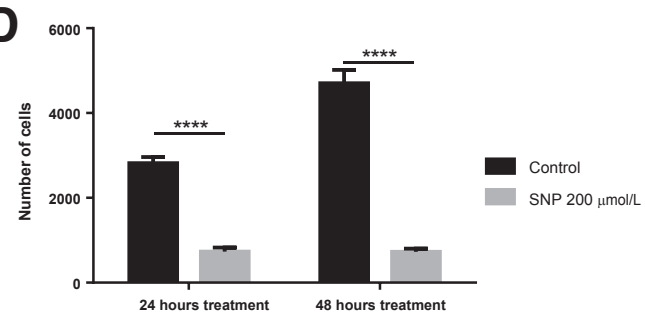

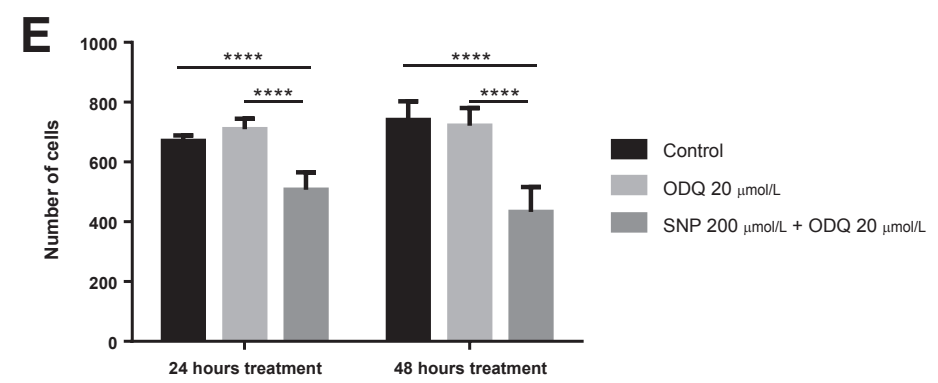

Figure 4 Proliferation of mouse and human aortic smooth muscle cells (SMCs) on pharmacological treatment. Human aortic smooth muscle cells (huAoSMCs; $\mathbf{A}-\mathbf{C}$ ) and primary mouse aortic SMCS (D and $\mathbf{E}$ ) harvested from wild-type animals were used. A: HuAoSMCs were treated for 24 or 48 hours with the N0-donor sodium nitroprusside (SNP; 50, 100, $200 \mu \mathrm{mol} / \mathrm{L})$ starting 24 hours after initial seeding, and cell number was assessed after the treatment interval. B: Effect of $10 \mu \mathrm{mol} / \mathrm{L} 1 \mathrm{H}-[1,2,4]$ oxadiazolo [4,3-a] quinoxalin-1-one (ODQ) treatment for 20 or 44 hours starting 4 hours after cell seeding on cell proliferation in huAoSMCs. Controls were treated using solvent (dimethylformamide). C: HuAoSMCs were treated for 24 hours with ODQ started 24 hours after seeding. Controls were treated with solvent and proliferation was assessed after the treatment interval. D: Proliferation of mouse AoSMCs treated for 24 or 48 hours with $200 \mu \mathrm{mol} / \mathrm{L}$ SNP started 24 hours after seeding. E: Mouse AoSMCs were treated for 24 or 48 hours with $20 \mu \mathrm{mol} / \mathrm{L}$ ODQ alone or combined with 200 $\mu \mathrm{mol} / \mathrm{L}$ SNP, controls received the solvent of ODQ (dimethylformamide). ${ }^{\star} P<0.05,{ }^{*} P<0.01$, and ${ }^{* * * \star} P<0.0001$.

myocardial infarction. In contrast, the current study points to a proatherosclerotic role of Gucyla3 in SMC as also demonstrated for the cGKI by Wolfsgruber et al..$^{25}$

In aortic lesions, collagen content was reduced in Gucyla3 $^{-1-}$ mice, whereas macrophage content remained unaltered. This further underlines the hypothesis that SMCs are accountable for the observed effect, although pharmacological activation of $\mathrm{sGC}$ exerted antiatherosclerotic effects in ApoE-deficient mice reportedly because of a modulation of macrophage functions. ${ }^{36}$ Recruitment, adhesion, and, finally, migration of monocytes and lymphocytes into the vessel wall and atherosclerotic plaques are crucial steps initiating and fostering the disease by local inflammatory processes. ${ }^{39,40}$ These processes may be modulated through Gucyla3, and reportedly activation of sGC limits inflammatory processes through cGMP and cGKI signaling. ${ }^{41,42}$ However, we did not find significant differences in macrophage content in lesions and also cytokine levels in murine plasma, reflecting the inflammatory processes were not altered. In contrast, phenotypically switched SMCs are responsible for matrix and collagen synthesis in response to injury. This transition from a quiescent, highly specialized contractile state (medial SMC) to a proliferative, migratory, and synthetic phenotype is accompanied by an altered localization of SMC toward the intima (intimal SMC).$^{37,43}$ As a consequence, intimal SMCs differ functionally from medial SMCs. ${ }^{3,37,44}$ SMCs in culture also undergo this phenotypical switch and mimic effects produced during the atherosclerosis process. ${ }^{45,46}$

Our in vitro data demonstrate that primary AoSMCs derived from Gucyla3-deficient mice migrate and proliferate to a lesser extent than AoSMCs from WT animals. The pharmacological inhibition of sGC in human AoSMCs mimicked the antiproliferative effect of Gucyla3 deficiency. Exogenously applied NO at high concentrations exhibited likewise an antiproliferative effect in human AoSMCs as well as in mouse WT AoSMCs. This is consistent with previous results using $\mathrm{NO}$ donors ${ }^{25}$ and corroborates the classic protective role of $\mathrm{NO}^{47}$ The antiproliferative effect of $\mathrm{NO}$ is most likely independent of sGC/cGKI, as demonstrated in murine cells in this study and also previously suggested, ${ }^{25,27,29,48}$ whereas sGC (current study) and 
A

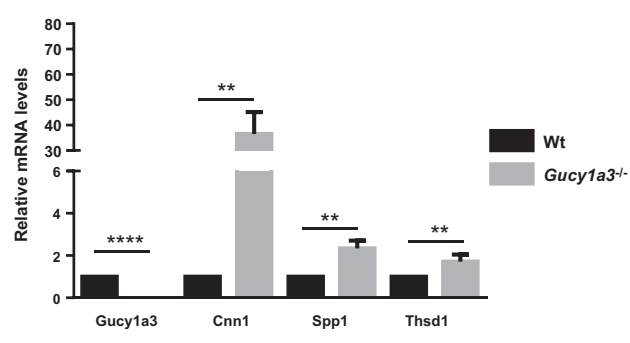

C

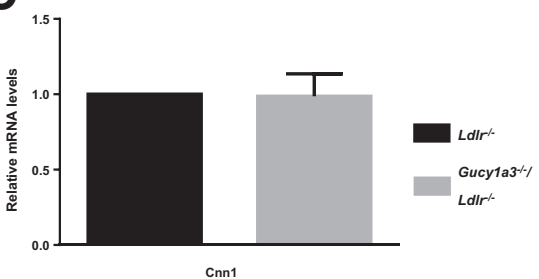

B

WT Gucy1a3\%

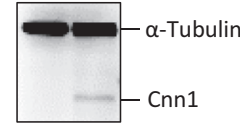

WT Gucy1a3\%
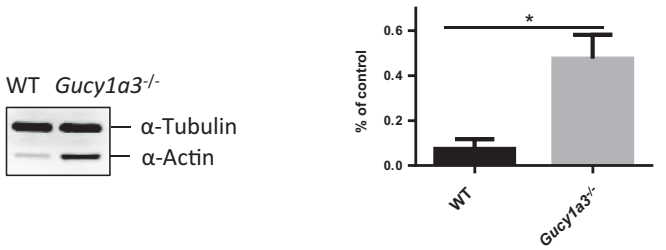

WT Gucy1a3\%

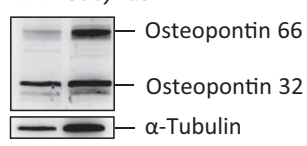

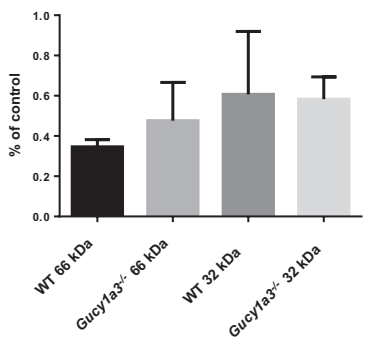

Figure 5 Expression of contractile and synthetic marker proteins in mouse aortic smooth muscle cells, aorta, and heart. A: Relative mRNA levels of Gucy1a3, as well as contractile (calponin, Cnn1) and synthetic marker proteins (osteopontin, Spp1; thrombospondin, Thsd1) in cultured primary mouse aortic smooth muscle cells from wild-type (WT) and Gucy $1 a 3^{-1-}$ animals. B: Western blot analysis of calponin, $\alpha$-actin, and osteopontin in cultured primary mouse aortic smooth muscle cells. Staining for $\alpha$-tubulin indicated equal loading of gels. For $\alpha$-actin and osteopontin, Western blot quantification is available on right panels. C: Relative mRNA levels of calponin in lesion-free aorta from $\mathrm{Ldll}^{-/-}$and Gucy $1 \mathrm{a}^{-/-} / \mathrm{Ldll}^{-/-}$animals under SD. $n=3$ to 4 per group (A and C). ${ }^{*} P<0.05,{ }^{* *} P<0.01$, and ${ }^{* * * *} P<0.0001$.

cGKI activation ${ }^{25}$ at low NO concentrations exert a proliferative effect onto SMCs.

Further support for the idea that SMCs deficient for Gucyla3 retain their highly specialized contractile phenotype comes from gene expression studies performed on cultured AoSMCs. Marker proteins like calponin and $\alpha$-actin, indicative of a contractile phenotype, are expressed at the mRNA and protein level at higher amounts in SMCs

\section{A}

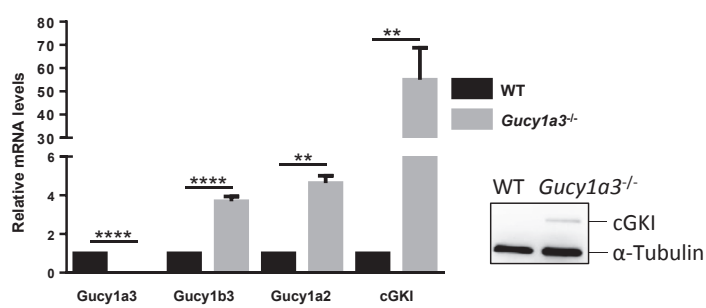

C

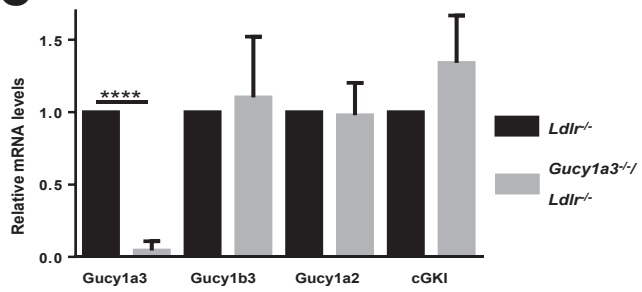

B

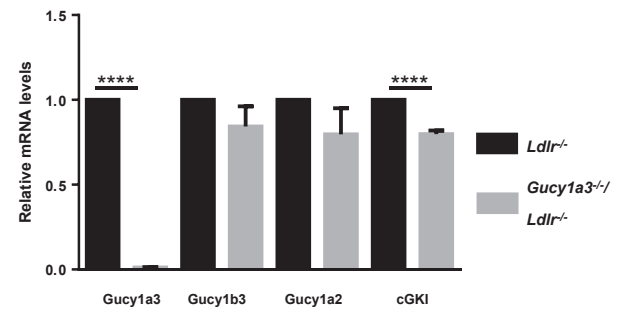

D

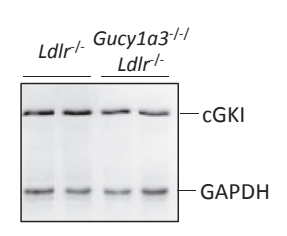

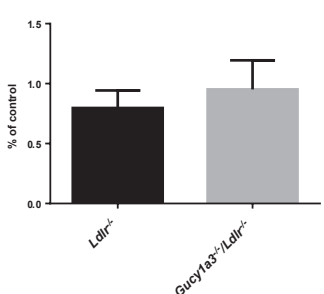

Figure 6 Expression of genes of the NO-cGMP pathway in mouse aortic smooth muscle cells, aorta, and heart. A: Relative mRNA levels of N0-cGMP genes in primary mouse aortic smooth muscle cells from wild-type (WT) and Gucy $1 a 3^{-/-}$animals and Western blot analysis of calponin. Staining for $\alpha$-tubulin indicates equal loading of gels. B: Relative mRNA levels of NO-cGMP genes in lesion-free aorta from $\mathrm{Ldll}^{-/-}$and Gucy $1 \mathrm{ab}^{-/-} / \mathrm{Ldll}^{-/-}$animals under SD. C and D: Relative mRNA levels of the NO-cGMP-cGKI pathway genes in heart from $L d l r^{-/-}$and Gucy $1 a 3^{-/-} /$Ldr $^{-/-}$animals receiving SD (C) and Western blot analysis and quantification of CGKI (D). Staining for glyceraldehyde-3-phosphate dehydrogenase (GAPDH) indicates equal loading of gels. $n=3$ to 4 per group (B and C). ${ }^{* *} P<0.01,{ }^{* * * *} P<0.0001$. 
isolated from Gucyla3-deficient mice than in cultured SMCs harvested from WT. In contrast, protein levels for osteopontin, which indicates a synthetic phenotype, were not altered. Interestingly, expression of calponin in lesionfree aortic tissue was not different between genotypes. This suggests that culture of SMCs initiates the down-regulation of calponin, $\alpha$-actin, and possibly other contractile proteins. Gucyla3 and thus sGC activity is required to promote this down-regulation. However, if SMCs are in their physiological environment in the absence of atherosclerotic environmental stimuli (lesion-free aorta) the phenotypic switching is also prevented in WT aorta. Currently, the molecular mechanisms that are involved in sGC/cGKI dependent promotion of phenotypic switching on injury are unknown. These may include the modulation of transcription factors being responsible for the preservation of the contractile state (eg, serum response factor, myocardin) or epigenetic mechanisms preventing access to key sites on the genome.

Several possible causes for the atheroprotective effect of Gucyla3 deficiency were excluded. First, other genes of the NO-cGMP-cGKI signaling pathway were expressed at higher levels in cultured primary AoSMCs on Gucyla3 deletion. This included Gucylab3, Gucyla2, and specifically $c G K I$. For the latter, an enhancement was also demonstrated at the protein level. However, in light of the fact that a distinct up-regulation was neither observed in lesion-free aortic tissue (where SMCs retain their contractile state) nor in heart tissue, we conclude that the differential expression level is related to the phenotypic switch occur-

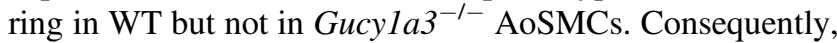

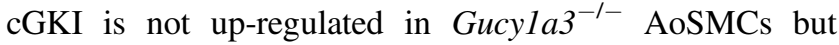
rather down-regulated in WT and the differences observed are more likely a consequence rather than being causative. Second, altered arterial pressure is unlikely having contributed to the protective effect of Gucyla3 deficiency.

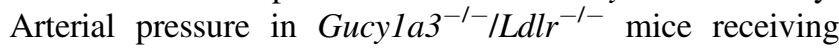
HFD was slightly increased, which is in accordance with previous studies. ${ }^{32,49}$ If anything, enhanced pressure is known to exacerbate atherosclerotic lesions. Third, body mass was unaffected and plasma lipid levels only minorly altered by Gucyla3 deficiency. Specifically, LDL levels were unchanged by the lack of Gucyla3 in proatherosclerotic $\mathrm{Ldll}^{-/-}$mice, excluding a metabolically driven protective effect.

In summary, our data demonstrate that loss of Gucyla3 exerts an atheroprotective effect in prone mice. The in vivo and in vitro data suggest that Gucyla3 and sGC activity promotes phenotypic switching of SMC from a quiescent contractile to a synthetic proliferative state. The preservation of the contractile phenotype may be fostered by inhibition of sGC in SMC and it remains to be clarified if this mechanism can be exploited therapeutically. However, a potential negative impact of sGC inhibition on platelet function that promotes platelet aggregation has to be considered.

\section{Acknowledgments}

We thank Maren Behrensen, Annett Liebers, Sandra Wrobel, Sabine Stark, and Petra Bruse for excellent technical assistance.

\section{Supplemental Data}

Supplemental material for this article can be found at http://dx.doi.org/10.1016/j.ajpath.2016.04.010.

\section{References}

1. Lusis AJ: Atherosclerosis. Nature 2000, 407:233-241

2. Weber C, Noels H: Atherosclerosis: current pathogenesis and therapeutic options. Nat Med 2011, 17:1410-1422

3. Lim S, Park S: Role of vascular smooth muscle cell in the inflammation of atherosclerosis. BMB Rep 2014, 47:1-7

4. Lincoln TM, Dey NB, Boerth NJ, Cornwell TL, Soff GA: Nitric oxide-cyclic GMP pathway regulates vascular smooth muscle cell phenotypic modulation: implications in vascular diseases. Acta Physiol Scand 1998, 164:507-515

5. Deloukas P, Kanoni S, Willenborg C, Farrall M, Assimes TL, Thompson JR, et al: Large-scale association analysis identifies new risk loci for coronary artery disease. Nat Genet 2013, 45:25-33

6. Erdmann J, Linsel-Nitschke P, Schunkert H: Genetic causes of myocardial infarction: new insights from genome-wide association studies. Dtsch Arztebl Int 2010, 107:694-699

7. Ibc T; Consortium CAD: Large-scale gene-centric analysis identifies novel variants for coronary artery disease. PLoS Genet 2011, 7: e 1002260

8. Kessler T, Erdmann J, Schunkert H: Importance of modern genomewide studies for the risk of myocardial infarction. Internist 2014, 55: $141-147$

9. Lieb W, Vasan RS: Genetics of coronary artery disease. Circulation 2013, 128:1131-1138

10. Samani NJ, Sci FM, Erdmann J, Ph D, Hall AS, Mangino M, Mayer B, Dixon RJ, Meitinger T, Braund P, Sc M, Wichmann H, Barrett JH, Tregouet A, Iles MM, Pahlke F, Pollard H, Lieb W, Cambien F, Fischer M, Path FRC, Blankenberg S, Balmforth AJ: Genomewide association analysis of coronary artery disease. N Engl J Med 2007, 357:443-453

11. Schunkert H, König IR, Kathiresan S, Reilly MP, Assimes TL, Holm H, et al: Large-scale association analysis identifies 13 new susceptibility loci for coronary artery disease. Nat Genet 2011, 43: $333-338$

12. Erdmann J, Stark K, Esslinger UB, Rumpf PM, Koesling D, Wit CD, Kaiser FJ, Braunholz D, Medack A, Fischer M, Zimmermann ME, Tennstedt S: Dysfunctional nitric oxide signalling increases risk of myocardial infarction. Nature 2013, 504:432-436

13. Friebe A, Koesling D: The function of NO-sensitive guanylyl cyclase: what we can learn from genetic mouse models. Nitric Oxide 2009, 21: 149-156

14. Mergia E, Russwurm M, Zoidl G, Koesling D: Major occurrence of the new alpha2betal isoform of NO-sensitive guanylyl cyclase in brain. Cell Signal 2003, 15:189-195

15. Nikpay M, Goel A, Won HH, Hall LM, Willenborg C, Kanoni S, et al A comprehensive 1000 Genomes-based genome-wide association meta-analysis of coronary artery disease. Nat Genet 2015, 47: $1121-1130$

16. Derbyshire ER, Marletta MA: Structure and regulation of soluble guanylate cyclase. Annu Rev Biochem 2012, 81:533-559 
17. Hofmann F, Feil R, Kleppisch T, Schlossmann J: Function of cGMPdependent protein kinases as revealed by gene deletion. Physiol Rev 2006, 86:1-23

18. Kauser K, da Cunha V, Fitch R, Mallari C, Rubanyi GM: Role of endogenous nitric oxide in progression of atherosclerosis in apolipoprotein E-deficient mice. Am J Physiol Heart Circ Physiol 2000, 278: H1679-H1685

19. Kuhlencordt PJ, Gyurko R, Han F, Scherrer-Crosbie M, Aretz TH, Hajjar R, Picard MH, Huang PL: Accelerated atherosclerosis, aortic aneurysm formation, and ischemic heart disease in apolipoprotein E/endothelial nitric oxide synthase double-knockout mice. Circulation 2001, 104:448-454

20. Kuhlencordt PJ, Hötten S, Schödel J, Rützel S, Hu K, Widder J, Marx A, Huang PL, Ertl G: Atheroprotective effects of neuronal nitric oxide synthase in apolipoprotein e knockout mice. Arterioscler Thromb Vasc Biol 2006, 26:1539-1544

21. Ponnuswamy P, Schröttle A, Ostermeier E, Grüner S, Huang PL, Ertl G, Hoffmann U, Nieswandt B, Kuhlencordt PJ: eNOS protects from atherosclerosis despite relevant superoxide production by the enzyme in apoE mice. PLoS One 2012, 7:e30193

22. Detmers PA, Hernandez M, Mudgett J, Hassing H, Burton C, Mundt S, Chun S, Fletcher D, Card DJ, Lisnock J, Weikel R, Bergstrom JD, Shevell DE, Hermanowski-Vosatka A, Sparrow CP, Chao YS, Rader DJ, Wright SD, Puré E: Deficiency in inducible nitric oxide synthase results in reduced atherosclerosis in apolipoprotein E-deficient mice. J Immunol 2000, 165:3430-3435

23. Kuhlencordt PJ, Chen J, Han F, Astern J, Huang PL: Genetic deficiency of inducible nitric oxide synthase reduces atherosclerosis and lowers plasma lipid peroxides in apolipoprotein E-knockout mice. Circulation 2001, 103:3099-3104

24. Feil R, Lohmann SM, de Jonge H, Walter U, Hofmann F: Cyclic GMP-dependent protein kinases and the cardiovascular system: insights from genetically modified mice. Circ Res 2003, 93:907-916

25. Wolfsgruber W, Feil S, Brummer S, Kuppinger O, Hofmann F, Feil R: A proatherogenic role for cGMP-dependent protein kinase in vascular smooth muscle cells. Proc Natl Acad Sci U S A 2003, 100: 13519-13524

26. Napoli C, de Nigris F, Williams-Ignarro S, Pignalosa O, Sica V, Ignarro LJ: Nitric oxide and atherosclerosis: an update. Nitric Oxide 2006, 15:265-279

27. Heller R, Polack T, Grabner R, Till U: Nitric oxide inhibits proliferation of human endothelial cells via a mechanism independent of cGMP. Atherosclerosis 1999, 144:49-57

28. Garg UC, Hassid A: Nitric oxide-generating vasodilators inhibit mitogenesis and proliferation of BALB/C 3 T3 fibroblasts by a cyclic GMP-independent mechanism. Biochem Biophys Res Commun 1990, 171:474-479

29. Ignarro LJ, Buga GM, Wei LH, Bauer PM, Wu GY, del Soldato P: Role of the arginine-nitric oxide pathway in the regulation of vascular smooth muscle cell proliferation. Proc Natl Acad Sci U S A 2001, 98 : 4202-4208

30. Napoli C, Paolisso G, Casamassimi A, Al-Omran M, Barbieri M, Sommese L, Infante T, Ignarro LJ: Effects of nitric oxide on cell proliferation: novel insights. J Am Coll Cardiol 2013, 62:89-95

31. Thomae KR, Nakayama DK, Billiar TR, Simmons RL, Pitt BR, Davies P: The effect of nitric oxide on fetal pulmonary artery smooth muscle growth. J Surg Res 1995, 59:337-343

32. Mergia E, Friebe A, Dangel O, Russwurm M, Koesling D: Spare guanylyl cyclase NO receptors ensure high NO sensitivity in the vascular system. J Clin Invest 2006, 116:1731-1737
33. Aherrahrou Z, Doehring LC, Ehlers E-M, Liptau H, Depping R, Linsel-Nitschke P, Kaczmarek PM, Erdmann J, Schunkert H: An alternative splice variant in Abcc6, the gene causing dystrophic calcification, leads to protein deficiency in $\mathrm{C} 3 \mathrm{H} / \mathrm{He}$ mice. J Biol Chem 2008, 283:7608-7615

34. Napoli C, Ignarro LJ: Nitric oxide-releasing drugs. Annu Rev Pharmacol Toxicol 2003, 43:97-123

35. Miller MR, Megson IL: Recent developments in nitric oxide donor drugs. Br J Pharmacol 2007, 151:305-321

36. Tsou CY, Chen CY, Zhao JF, Su KH, Lee HT, Lin SJ, Shyue SK, Hsiao SH, Lee TS: Activation of soluble guanylyl cyclase prevents foam cell formation and atherosclerosis. Acta Physiol (Oxf) 2014, 210: 799-810

37. Doran AC, Meller N, McNamara CA: Role of smooth muscle cells in the initiation and early progression of atherosclerosis. Arterioscler Thromb Vasc Biol 2008, 28:812-819

38. Herve D, Philippi A, Belbouab R, Zerah M, Chabrier S, CollardeauFrachon S, Bergametti F, Essongue A, Berrou E, Krivosic V, Sainte-Rose C, Houdart E, Adam F, Billiemaz K, Lebret M, Roman S, Passemard S, Boulday G, Delaforge A, Guey S, Dray X, Chabriat H, Brouckaert P, Bryckaert M, Tournier-Lasserve E: Loss of alpha1betal soluble guanylate cyclase, the major nitric oxide receptor, leads to moyamoya and achalasia. Am J Hum Genet 2014, 94:385-394

39. Moore KJ, Tabas I: Macrophages in the pathogenesis of atherosclerosis. Cell 2011, 145:341-355

40. Doring Y, Drechsler M, Soehnlein O, Weber C: Neutrophils in atherosclerosis: from mice to man. Arterioscler Thromb Vasc Biol 2015, 35:288-295

41. Ahluwalia A, Foster P, Scotland RS, McLean PG, Mathur A, Perretti M, Moncada S, Hobbs AJ: Antiinflammatory activity of soluble guanylate cyclase: cGMP-dependent down-regulation of Pselectin expression and leukocyte recruitment. Proc Natl Acad Sci U S A 2004, 101:1386-1391

42. Werner CG, Godfrey V, Arnold RR, Featherstone GL, Bender D, Schlossmann J, Schiemann M, Hofmann F, Pryzwansky KB: Neutrophil dysfunction in guanosine 3',5'-cyclic monophosphatedependent protein kinase I-deficient mice. J Immunol 2005, 175: 1919-1929

43. Alexander MR, Owens GK: Epigenetic control of smooth muscle cell differentiation and phenotypic switching in vascular development and disease. Annu Rev Physiol 2012, 74:13-40

44. Rudijanto A: The role of vascular smooth muscle cells on the pathogenesis of atherosclerosis. Acta Med Indones 2007, 39:86-93

45. Dzau VJ, Braun-Dullaeus RC, Sedding DG: Vascular proliferation and atherosclerosis: new perspectives and therapeutic strategies. Nat Med 2002, 8:1249-1256

46. Campbell GR, Campbell JH: Smooth muscle phenotypic changes in arterial wall homeostasis: implications for the pathogenesis of atherosclerosis. Exp Mol Pathol 1985, 42:139-162

47. Jeremy JY, Rowe D, Emsley AM, Newby AC: Nitric oxide and the proliferation of vascular smooth muscle cells. Cardiovasc Res 1999, 43:580-594

48. Feil R, Feil S, Hofmann F: A heretical view on the role of NO and cGMP in vascular proliferative diseases. Trends Mol Med 2005, 11 : $71-75$

49. Buys ES, Sips P, Vermeersch P, Raher MJ, Rogge E, Ichinose F, Dewerchin M, Bloch KD, Janssens S, Brouckaert P: Gender-specific hypertension and responsiveness to nitric oxide in sGCalpha1 knockout mice. Cardiovasc Res 2008, 79:179-186 